\title{
Gender-related differences in cue-elicited cravings in Internet gaming disorder: The effects of deprivation
}

\author{
GUANGHENG DONG ${ }^{1}$, HUI ZHENG ${ }^{2}$, XIAOYUE LIU ${ }^{2}$, YIFAN WANG ${ }^{3}$, XIAOXIA DU ${ }^{4}$ and MARC N. POTENZA ${ }^{5,6,7,8 *}$ \\ ${ }^{1}$ School of Psychology, Fujian Normal University, Fuzhou, P. R. China \\ ${ }^{2}$ Institute of Psychological and Brain Sciences, Zhejiang Normal University, Jinhua, P. R. China \\ ${ }^{3}$ School of Psychology and Cognitive Science, East China Normal University, Shanghai, P. R. China \\ ${ }^{4}$ Department of Physics, Shanghai Key Laboratory of Magnetic Resonance, East China Normal University, Shanghai, P. R. China \\ ${ }^{5}$ Department of Psychiatry and Neurobiology, Child Study Center, Yale University School of Medicine, New Haven, CT, USA \\ ${ }^{6}$ Connecticut Council on Problem Gambling, Wethersfield, CT, USA \\ ${ }^{7}$ National Center on Addiction and Substance Abuse, Yale University School of Medicine, New Haven, CT, USA \\ ${ }^{8}$ Connecticut Mental Health Center, New Haven, CT, USA
}

(Received: September 15, 2018; revised manuscript received: September 16, 2018; accepted: October 30, 2018)

\begin{abstract}
Background: Online gaming has become a popular leisure activity, in which males more frequently develop Internet gaming disorder (IGD) compared to females. However, gender-related neurocognitive differences have largely not been systematically investigated in IGD. Methods: Cue-elicited-craving tasks were performed before game playing and immediately after deprivation operationalized as a forced break from gaming when the Internet was disconnected. Ninety-nine subjects with IGD (27 males and 22 females) or recreational game use (RGU; 27 males and 23 females) provided functional MRI and subjective data. Analyses investigating effects of group (IGD and RGU) $\times$ gender (male and female) at different times (pre-gaming, post-gaming, and post-pre) on cue-elicited craving and brain responses were performed. Correlations between brain responses and subjective measures were calculated. Results: In pre-, post-, and post-pre tests, significant gender-by-group interactions ( $p<.001$, cluster size $>15$ voxels) were observed in the left dorsolateral prefrontal cortex (DLPFC). Further analyses of the DLPFC cluster showed that in post-pre comparisons, results were related to less engagement of the DLPFC in IGD, especially in females. In addition, at posttest, significant interactions were observed in the caudate, as females with IGD showed greater activation as compared to those with RGU. Discussion: The results raise the possibility that women with RGU may show better executive control than men when facing gaming cues, which may provide resiliency against developing IGD; however, once they develop IGD, their gaming may impair their executive control and enhance their cravings for gaming, which may make it more difficult to quit gaming.
\end{abstract}

Keywords: Internet gaming disorder, gender, craving, executive control, dorsolateral prefrontal cortex, caudate

\section{INTRODUCTION}

Online gaming has become a popular leisure activity, and most individuals who play online games do so in a recreational, controlled manner, without showing symptoms of addiction, craving, or withdrawal (Kuss \& Griffiths, 2012; Montag \& Reuter, 2015; Viriyavejakul, 2008). However, a small proportion of people $(0.3 \%-1.0 \%)$ exhibit poor control over their desires to play Internet games and qualify for a diagnosis of Internet gaming disorder (IGD; Kiraly et al., 2017; Przybylski, Weinstein, \& Murayama, 2017). IGD has been associated with negative consequences including physical and psychological disorders, social deficits, and/or poor academic performance (King \& Delfabbro, 2018; Lukavska, 2018; Petry et al., 2014; Rumpf et al., 2018; Starcevic \& Billieux, 2018).

Multiple studies have shown that male online game players are more likely to develop IGD than females (Borgonovi, 2016). Studies have suggested that a minority of female and a majority of male adolescents play video games (Desai, Krishnan-Sarin, Cavallo, \& Potenza, 2010), and the rates of IGD development appear particularly high in males. For example, studies have found that about $6.3 \%$ of boys and $2.4 \%$ of girls in China ( $\mathrm{Li}, \mathrm{Yu}$, Zhang, \& Jin, 2015 ) and $3.6 \%$ of boys and $1.9 \%$ of girls in Korea (Ha \& Hwang, 2014) may experience IGD. Similar proportions have been observed in Taiwan (Ko et al., 2014) and

\footnotetext{
* Corresponding authors: Prof. Guangheng Dong, PhD; School of Psychology, Fujian Normal University, 1 Keji Road, Fujian Province, Fuzhou 321004, P. R. China; Phone: +86 1586794 9909; Fax: +86 5798228 2549; E-mail: dongguangheng@zjnu.edu.cn; Prof. Marc N. Potenza, PhD, MD; Department of Psychiatry and Neurobiology, Child Study Center, Yale University School of Medicine, 1 Church Street, New Haven, CT 06511, USA; Phone: +1 203737 3553; Fax: +1 203737 3591; E-mail: Marc.Potenza@yale.edu
}

This is an open-access article distributed under the terms of the Creative Commons Attribution-NonCommercial 4.0 International License, which permits unrestricted use, distribution, and reproduction in any medium for non-commercial purposes, provided the original author and source are credited, a link to the CC License is provided, and changes - if any - are indicated. 
elsewhere (Borgonovi, 2016). Video gaming problems in high-school students in the United States have been estimated at $4.9 \%$ of gamers, with boys were more likely to report gaming problems $(5.8 \%)$ than girls $(3.0 \%)$ (Desai et al., 2010). Data suggest that these differences are not related to differences in gaming skills as studies have observed that female gamers show comparable gaming skills to male gamers (Shen, Ratan, Cai, \& Leavitt, 2016).

Gender-related differences have been observed in multiple addictive behaviors, including those relating to alcohol consumption (Bobzean, DeNobrega, \& Perrotti, 2014), illicit drug use (Moran-Santa Maria, Flanagan, \& Brady, 2014), and gambling (González-Ortega, Echeburúa, de Corral, \& Polo-López, 2015; Potenza et al., 2001), including in rodent models (Hu, Crombag, Robinson, \& Becker, 2004). Data suggest that females progress more rapidly from behavioral initiation to addiction (Becker, McClellan, \& Reed, 2017; Bobzean et al., 2014; Moran-Santa Maria et al., 2014; Zakiniaeiz, Cosgrove, Mazure, \& Potenza, 2017), and they exhibit greater vulnerability than males in terms of treatment outcome (Becker, 2016; Perry, Westenbroek, Jagannathan, \& Becker, 2015; Sanchis-Segura \& Becker, 2016). In addition, engaging in pleasurable activities activates reward systems, and females have shown greater dorsolateral striatal responses to drugs than males (Berridge \& Kringelbach, 2015), which suggest potentially different neural mechanisms underlying responses in addictive processes.

As a proposed behavioral addiction, IGD has shown similarities to these other addictions, including diminished executive control (Dong, Li, Wang, \& Potenza, 2017; Wang et al., 2016; Yao et al., 2017), enhanced reward sensitivity (Brand, Young, Laier, Wolfling, \& Potenza, 2016; Dong, $\mathrm{Hu}$, \& Lin, 2013; Dong, Huang, \& Du, 2011; Dong \& Potenza, 2014), disadvantageous decision-making (Dong \& Potenza, 2016; Petry, Zajac, \& Ginley, 2018; Wang et al., 2016), increased brain responses to gaming cues (Dong, Wang, Du, \& Potenza, 2017), and poorer functional connectivity in executive-control networks (Dong, Lin, Hu, Xie, \& Du, 2015). Most studies, to date, have involved entirely or predominantly in male samples. Given genderrelated differences in other addictive behaviors and disorders, studies are needed to examine the extent to which findings in male populations with IGD may extend to or differ from those in female populations with IGD.

Responses in reward systems have been implicated in multiple addictions. Craving is a motivation that promotes engagement in addictive behaviors (Dong, Wang, Du, et al., 2017; Potenza et al., 2003; Sayette, 2016; Sinha \& Li, 2007). Craving is a key feature of addictions and is included as an inclusionary criterion for substance-use disorders (American Psychiatric Association, 2013). It is a target for behavioral therapies like cognitive-behavioral therapy (Potenza et al., 2013). The neural correlates of craving in both substance and behavioral addictions include cortico-striatal-limbic circuitry (Kilts, Gross, Ely, \& Drexler, 2004; Kober et al., 2016; Potenza et al., 2012). Multiple studies have identified gender-related differences in craving using cue-elicited craving tasks. For example, one study found that men with pathological gambling are sensitive to gambling-related cues, whereas women are more sensitive to negative mood states (Grant \& Kim, 2002). Other data suggest that seeking behaviors of males are more related to positive reinforcement motivations, whereas females' behaviors are more related to negative reinforcement motivations (Zakiniaeiz, Cosgrove, Potenza, $\&$ Mazure, 2016). The extent to which such differences may extend to IGD warrants direct investigation.

Deprivation occurs when people are not allowed to do something that they desire. In addictions, deprivation may occur, for example, when somebody wishes to consume drugs, but is not allowed to do so. Deprivation may also occur when engagement in a behavior is forcibly stopped. In individuals with addictions, deficits in reward capacity may relate to feelings of deprivation, craving, and mood instability (Detar, 2011; Field, Mogg, \& Bradley, 2004; Havermans, van Schayck, Vuurman, Riedel, \& van den Hurk, 2017; Taylor, Langdon, \& Campion, 2005). Studies have linked increased salience of smoking-related cues to nicotine deprivation (Robinson \& Berridge, 2008), with visual processing of objects contributing to the phenomenon (Havermans et al., 2017). During periods of nicotine deprivation, heightened autonomic arousal has been observed in smokers (Abrams et al., 2017; Breland, Buchhalter, Evans, \& Eissenberg, 2002). These and other findings suggest that smokers' attention is biased toward smoking cues, thus potentially influencing motivations and reward-related processes (Hester \& Luijten, 2014; Jasinska, Stein, Kaiser, Naumer, \& Yalachkov, 2014; Potenza et al., 2012; Volkow, Wang, Tomasi, \& Baler, 2013). However, to date, little attention has been paid to the effect of deprivation in IGD, and a study of gender-related differences in these processes is needed.

Based on the above literature, we hypothesized that deprivation could elicit stronger cravings in IGD subjects as compared to those with recreational game use (RGU) during a cue-exposure task, and that there would be differences between male and female subjects, with males showing stronger cravings than females. Second, we hypothesized that gaming cues would activate cortical and striatal regions in males and females with differences relating to gaming status (IGD and RGU), and that these activations would relate to self-reported craving in males and females. Third, we hypothesized that both males and females with IGD would show greater craving and greater cortical and striatal brain activations following deprivation (operationalized as a forced break from gaming) as compared to prior to gaming.

\section{MATERIALS AND METHODS}

\section{Subjects}

Ninety-nine right-handed university students [IGD: 27 males and 22 females; recreational game use (RGU): 27 males and 23 females] were recruited for this study. Demographic information and group differences have been depicted in Table 1. All participants underwent structured psychiatric interviews (Mini International Neuropsychiatric Interview) proposed by an experienced psychiatrist (Lecrubier et al., 1997) and those with psychiatric/neurological disorders were excluded. In addition, no subjects reported previous experience with gambling or illicit drugs (e.g., marijuana and heroin). All subjects reported having played League of Legends ( $L O L$, Riot Games) for more than 1 year. 
Table 1. Demographic information and group differences

\begin{tabular}{lcccccc}
\hline & $\begin{array}{c}\text { Female, RGU } \\
(N=23)\end{array}$ & $\begin{array}{c}\text { Male, RGU } \\
(N=27)\end{array}$ & $\begin{array}{c}\text { Female, IGD } \\
(N=22)\end{array}$ & $\begin{array}{c}\text { Male, IGD } \\
(N=27)\end{array}$ & $F$ & $p$ \\
\hline Age (mean $\pm S D)$ & $21.96 \pm 1.92$ & $23.07 \pm 1.86$ & $21.50 \pm 1.87$ & $22.19 \pm 2.42$ & 1.62 & .150 \\
IAT score (mean $\pm S D)$ & $33.70 \pm 6.66$ & $34.00 \pm 7.03$ & $59.18 \pm 9.55$ & $64.59 \pm 11.13$ & 74.88 & $.000^{* * *}$ \\
DSM-5 score (mean $\pm S D)$ & $2.22 \pm 1.17$ & $2.00 \pm 1.07$ & $5.55 \pm 1.06$ & $5.85 \pm 0.95$ & 96.39 & $.000^{* * *}$ \\
Game playing per week $(\mathrm{hr})$ & $14.74 \pm 3.17$ & $14.30 \pm 10.62$ & $15.05 \pm 6.64$ & $14.59 \pm 8.34$ & 0.85 & .352 \\
$\quad$ & & & & & \\
$\quad$ (mean $\pm S D$ ) & $26.35 \pm 7.42$ & $29.00 \pm 7.77$ & $29.55 \pm 9.66$ & $39.70 \pm 12.44$ & 9.69 & $.000^{* * *}$ \\
Gaming history (months) & $30.52 \pm 19.59$ & $32.37 \pm 12.33$ & $47.41 \pm 19.44$ & $50.78 \pm 16.33$ & 9.26 & $.000^{* * *}$ \\
Self-reported craving & &
\end{tabular}

Note. SD: standard deviation; IAT: Internet Addiction Test; RGU: recreational game use; IGD: Internet gaming disorder; DSM-5: fifth edition of Diagnostic and Statistical Manual of Mental Disorders.

IGD participants were selected based on scores on Young's Internet Addiction Test (IAT) and the nine fifth edition of Diagnostic and Statistical Manual of Mental Disorders (DSM-5) criteria of IGD (Petry et al., 2014; Young, 2009). Participants were diagnosed with IGD if they satisfied both of the following criteria: (a) scored 50 or higher on the IAT and (b) met at least five DSM-5 criteria.

RGU participants needed to score less than 50 on the IAT and meet less than five DSM-5 criteria for IGD. Second, they needed to play $L O L$ for at least 1 year, more than $14 \mathrm{hr}$ per week, and 5 or more days in a week, similar to IGD participants (Dong, Li, et al., 2017), but without showing any symptoms of physical or psychological dependence (see Table 1 for details).

\section{Experimental protocol}

The protocol consisted of three sections: performance of a cue-elicited-craving task, game-playing and the creation of deprivation, and performance of a cue-elicited-craving task during deprivation (Figure 1A).
The cue-craving task used at pre-and post-gaming times

The cue-elicited-craving task was performed at pre- and post-gaming times (Figure 1B), as detailed in our previous studies (Dong, Wang, Du, et al., 2017) and described briefly below. In one typical trial, after a $500 \mathrm{~ms}$ fixation, subjects were asked to respond ( $1=$ yes, $2=$ no, with counter-balancing between subjects) whether there is a face in the stimulus (up to 4,000 ms). After a jitter (1,500-3,500 ms), the evaluation stage followed, and subjects were asked to report the intensities of their craving [on a scale from 1 (low) to 5 (high)] for the relevant stimuli $(4,000 \mathrm{~ms}$, will be terminated by a button press). After another jitter (1,500 $3,500 \mathrm{~ms})$, the next trial ensued. We focused our analyses on the "response" stage in data analysis (Figure 1B).

Eighty pictures divided into two categories were used in this study: gaming-related and typing-related pictures (neutral baseline). Fifty percent of all pictures within each category contained a face, and the other half contained a hand. As shown in Figure 1C, in gaming-related stimuli, somebody is displayed playing a game on a computer, with

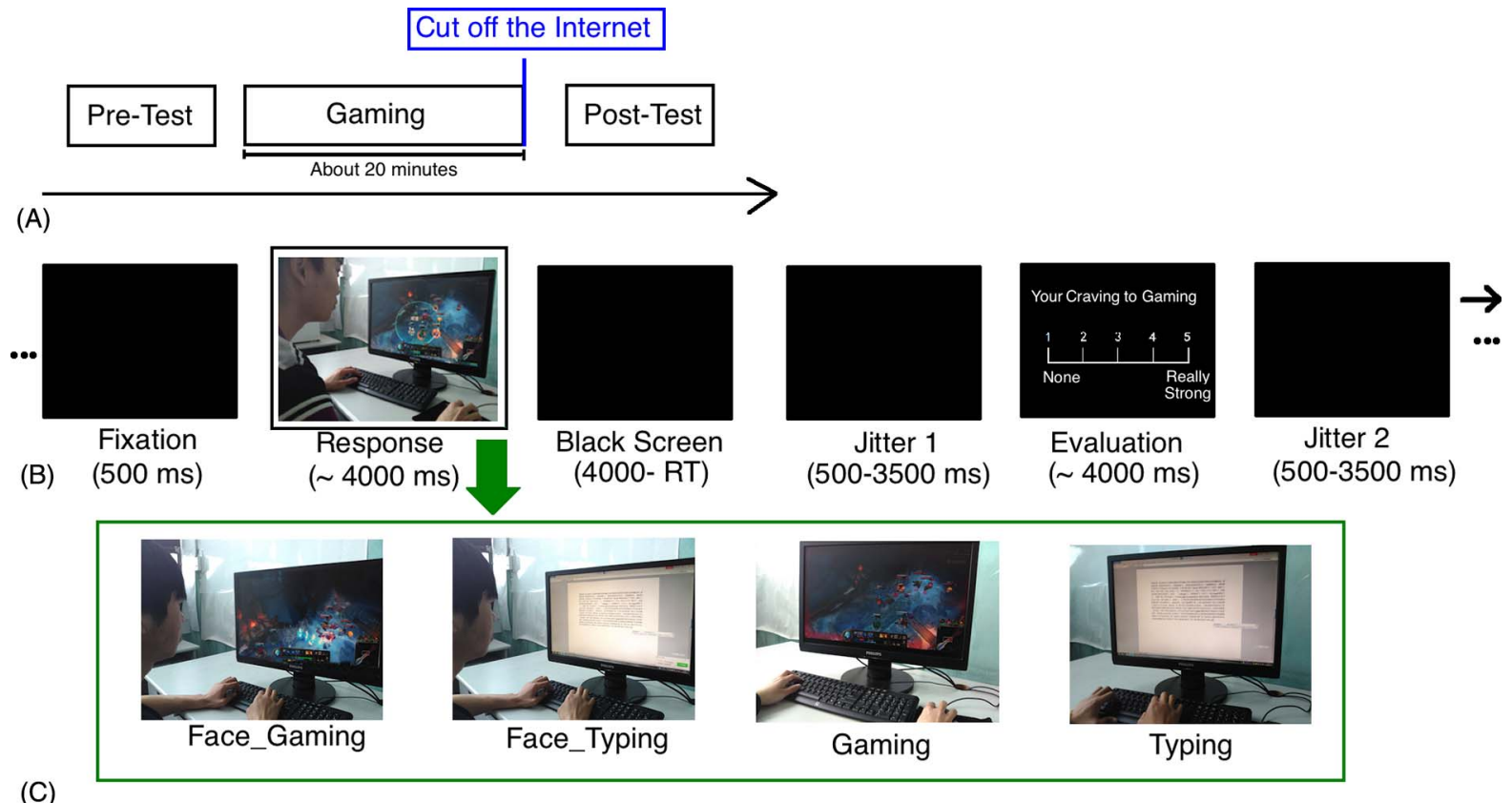

Figure 1. The structure of this study. (A) A schematic diagram of the study procedure. (B) The timeline of one trial in the cue-elicitation craving task. (C) Example stimuli used in this study 
some stimuli showing faces and others showing hands. In the typing-related pictures, background imagery was similar except that somebody is typing rather than gaming.

\section{Controlling for stimuli pictures}

All pictures were taken in the same place (white wall background and a white desk with a black screen). Male and female faces were in proportion of 50:50 in both conditions. Subjects cannot distinguish emotions as only single sides of faces were included, which is to control for potentially confounding factors (e.g., emotions and accessories).

\section{Controlling for task-performance motivation}

Before scanning, participants were informed that a guaranteed 50 Yuan ( $\approx 8$ US\$) would be paid for their participation, and if they performed well, extra money would be presented, with an additional 0-50 Yuan based on their task performance (accuracy rates $\times 50$ ). Accuracy rates (for identification of pictures with faces or no faces) were expected to approach/reach ceiling effects for the two groups.

\section{Controlling for task repetition}

The fMRI tasks in the pre- and post-tests were of the same type but differed in content, in order to avoid/minimize possible repetition effects. We generated two copies of the task with different items (Copies A and B). Half of each group of participants took part in an "A-B" sequence, and the other half received a " $\mathrm{B}-\mathrm{A}$ " sequence in their pre- and post-gaming scans.

\section{Forced break from gaming: The creation of deprivation}

In the scanner, subjects were asked to play $L O L$ for one round. In general, one round of $L O L$ takes more than half an hour. However, at about 20 min later, participants started playing (after they engaged in fighting with their enemy for about $5 \mathrm{~min}$ ), we suddenly shut off the Internet connection purposefully (participants were not instructed about the intentional nature of the disconnection). In this manner, deprivation was generated. About 4 min later, we informed participants there was something wrong with the Internet connection and asked them to perform another cue-elicitedcraving task.

We selected the time point after participants started fighting with the enemy for about $5 \mathrm{~min}$ (at about $20 \mathrm{~min}$ after they started playing), because we believe that the fighting stage is climactic and thus the time at which it is best to create deprivation for inducing craving. Before this stage, all players are typically accumulating strength and moving to the enemy camp. In addition, to promote participants' familiarity with their gaming experiences, they were asked to log into the game with their own account.

\section{Data collection}

Structural images were collected using a T1-weighted threedimensional spoiled gradient-recalled sequence covering the whole brain ( 176 slices, repetition time $=1,700 \mathrm{~ms}$, echo time $\mathrm{TE}=3.93 \mathrm{~ms}$, slice thickness $=1.0 \mathrm{~mm}$, skip $=0 \mathrm{~mm}$, flip angle $=15$, inversion time $=1,100 \mathrm{~ms}$, field of view $=240 \times$ $240 \mathrm{~mm}$, in-plane resolution $=256 \times 256)$. Functional MRI was performed on a $3 \mathrm{~T}$ scanner (Siemens Trio, Malvern, PA, USA) with a gradient-echo EPI T2*-weighted-sensitive pulse sequence in 33 slices (interleaved sequence, $3 \mathrm{~mm}$ thickness, $\mathrm{TR}=2,000 \mathrm{~ms}, \mathrm{TE}=30 \mathrm{~ms}$, flip angle $90^{\circ}$, field of view $220 \times 220 \mathrm{~mm}^{2}$, matrix $64 \times 64$ ) (Dong, Hu, Lin, \& Lu, 2013). Stimuli were presented using an in vivo synchronous system (www.invivocorp.com) through a screen in the head coil, enabling participants to view the stimuli. The whole experiment lasted for around an hour [pre-test and post-test (14 min each), T-1 structural (6 min), prepare for scanning and the time between different tasks (6 min), and gaming $(\sim 20 \mathrm{~min})]$.

\section{Data preprocessing}

The functional data were analyzed using standard steps proposed by SPM12 (http://www.fil.ion.ucl.ac.uk/spm) and Neuroelf (http://neuroelf.net), as described previously (DeVito et al., 2012; Krishnan-Sarin et al., 2013). Images were slice-timed, reoriented, and realigned to the first volume, with T1-co-registered volumes used to correct for head movements. Images were then normalized to Montreal Neurological Institute space and spatially smoothed using a 6-mm FWHM Gaussian kernel. No subjects were removed from analysis because of head motion (the exclusion criteria were $2 \mathrm{~mm}$ in directional movement or $2^{\circ}$ in rotational movement). A general linear model (GLM) was applied to identify blood oxygen-level-dependent (BOLD) activation in relation to brain activities. Different types of trials (gaming-related, typing-related, incorrect, or missed) were separately convolved with a canonical hemodynamic response function to form task regressors. The duration of each trial was 4,000 ms. The GLMs also included the six head-movement parameters derived from the realignment stage; the time they played the game in the scanner; and the time they played online games, age, and self-reported cravings. We focused analyses on voxels that were significantly activated for each event during the "response" stage.

\section{Comparisons}

We performed three analyses investigating group-by-gender interactions on: (a) cue-elicited craving before gaming [Gender (male and female) $\times$ Group (IGD and RGU) at pre-test]; (b) cue-elicited craving during deprivation [Gender (male and female) $\times$ Group (IGD and RGU) at post-test]; and (c) cue-elicited craving in post-pre test [Gender (male and female) $\times$ Group (IGD and RGU) at post-test using subjects' brain features at pre-test as a focus in the GLM model]. Voxel-wise $2 \times 2$ (Factor 1: IGD and RGU; Factor 2 : male and female) repeated-measure analyses were conducted. In these analyses, we first investigated the interactions and main effects and then tested each factor to find factors underlying the interactions. The imaging results were corrected using family-wise error correction at voxel-level $p<.001$, with an extent of at least 15 voxels. 


\section{Correlation analyses}

We first compared brain activations in the aforementioned comparisons and took surviving clusters as regions of interest (ROIs) to correlate with behavioral measures. For each ROI, a representative BOLD beta value was obtained by averaging the signal of all the voxels within it.

\section{Ethics}

This experiment was approved by the Human Investigations Committee of Zhejiang Normal University and conformed to The Code of Ethics of the World Medical Association (Declaration of Helsinki). All participants provided written informed consent before scanning.

\section{RESULTS}

\section{Behavioral performance}

As the task is easy and we did not ask participants to respond as soon as possible, the accuracy rates and response times in the current study may provide limited information (see Supplementary Material 1.1 and 1.2). At pre-test and at post-test, individuals with IGD reported stronger craving than did those with RGU, with males and females showing similar levels of craving. Comparable levels of craving were reported prior to gaming and following gaming deprivation during the forced break (Supplementary Material 1.3).

\section{Imaging results}

The main effects of gender and group in the different comparisons are presented in Table 1, with relevant figures presented in the Supplementary Material.

\section{Gender-by-group effect prior to gaming}

Prior to gaming, significant interactions were found in the left dorsolateral prefrontal cortex (DLPFC) (Figure 2A; Table 1). Post-hoc analysis of the DLPFC finding indicated that while females with IGD and RGU showed similar activations of this region, males with IGD showed less activation than males with RGU (Figure 2B). A significant negative correlation was observed between the brain responses in the DLPFC and self-reported craving in the entire sample, and this relationship was significant in males but not females (Figure 2C and D).

\section{Gender-by-group effect post-gaming during deprivation}

Following the forced break, significant gender-by-group interactions were observed in the left DLPFC and the caudate (Figure 3A; Table 2). Post-hoc analysis of the left DLPFC finding showed that the DLPFC activity was similar

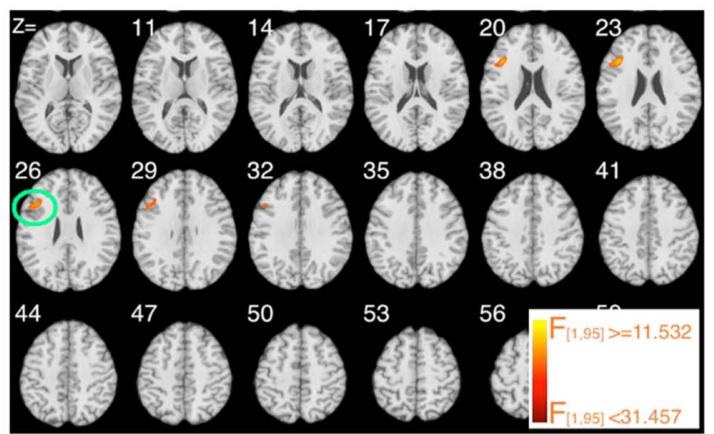

(A)

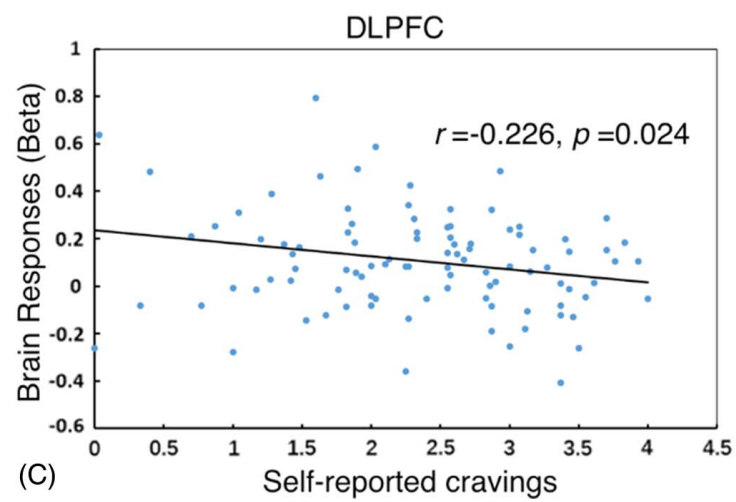

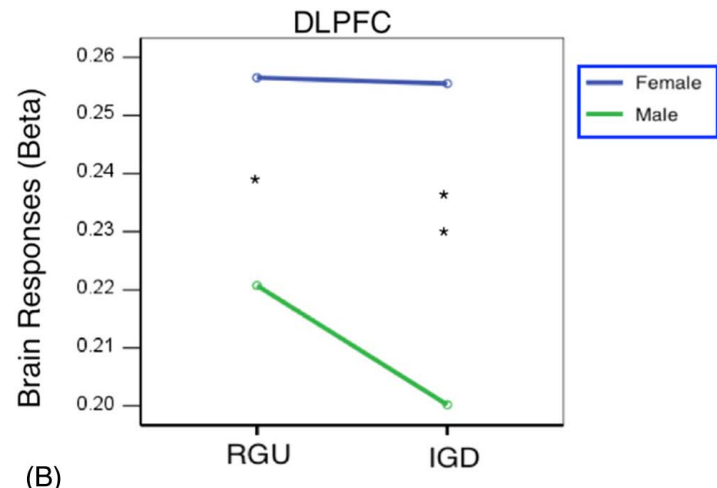

(B)

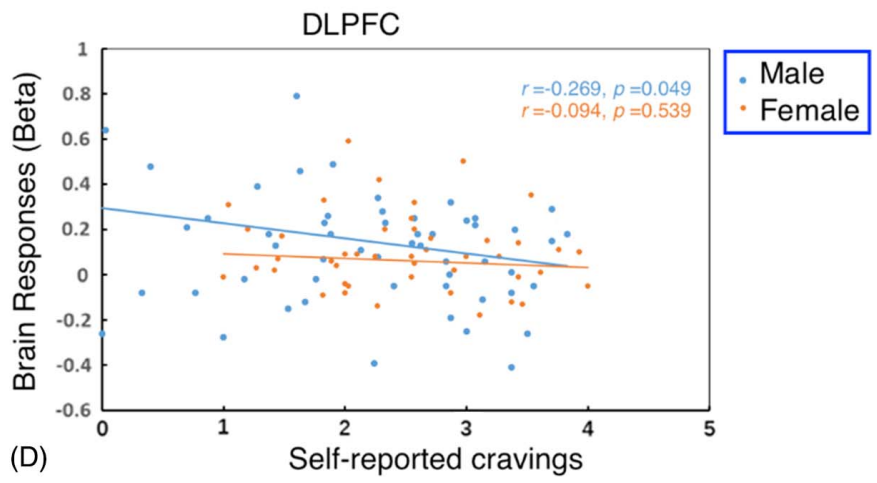

Figure 2. Gender-by-group interactions prior to gaming (pre-gaming). (A) The DLPFC showed a significant gender-by-group interaction prior to gaming. (B) Post-hoc analysis showed that the DLPFC difference was related to the IGD group relative to the RGU group showing relatively blunted DLPFC activation in males but not females. DLPFC activation was correlated with self-reported craving in all subjects (C) and in males but not females (D) 


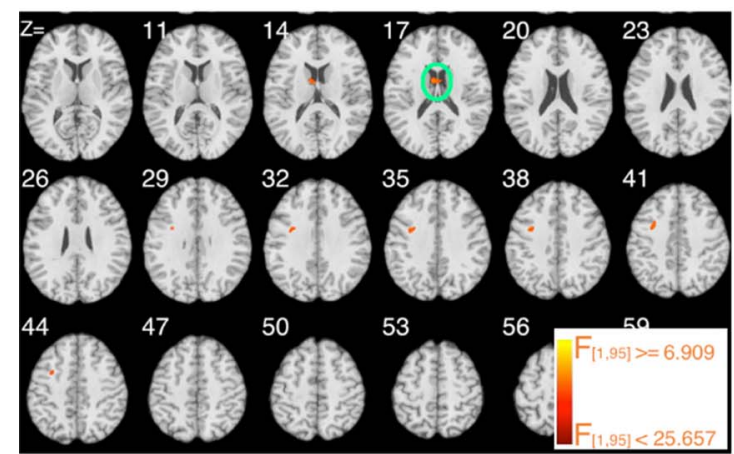

(A)

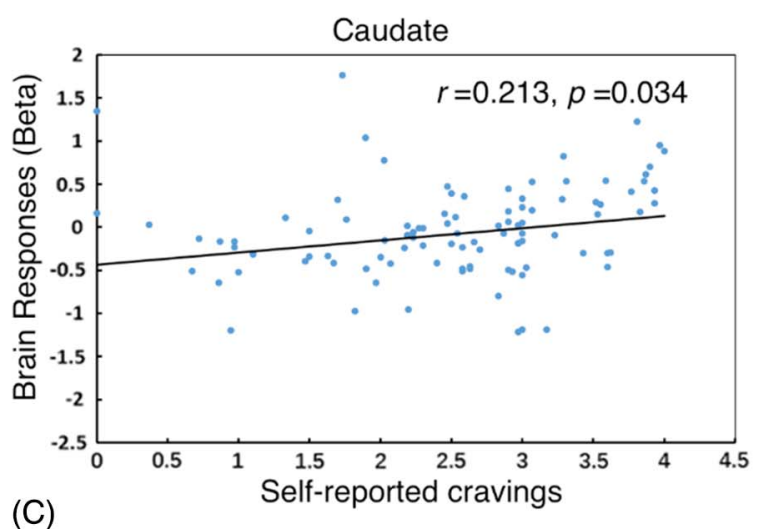

(C)
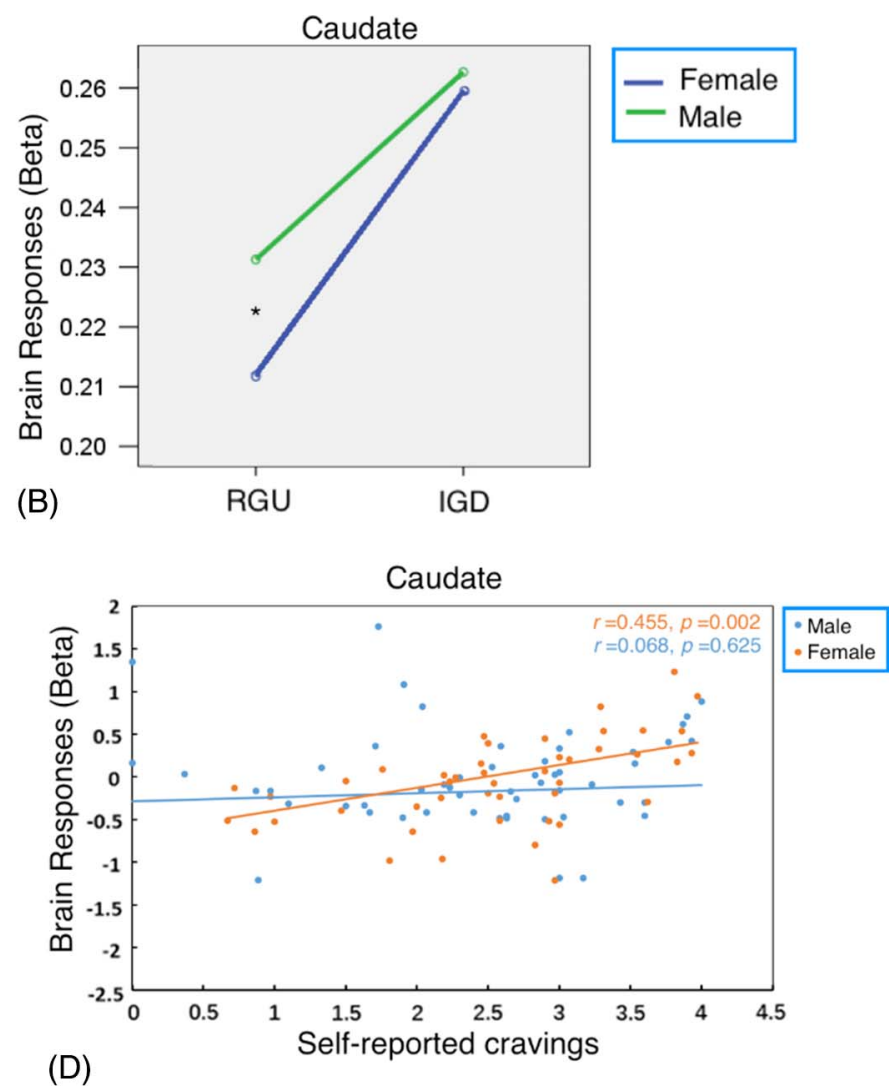

Figure 3. Gender-by-group interaction following gaming and during a forced break (post-gaming). (A) The caudate showed a significant gender-by-group interaction following gaming. (B) Post-hoc analysis showed that among RGU subjects, males showed greater caudate activation, whereas among IGD subjects, no gender-related difference was observed. However, caudate activation was greater in IGD relative to RGU subjects in both male and female subjects. Caudate activation positively correlated with self-reported craving in all subjects (C) and in females but not males (D)

in females with IGD and females with RGU, and males with IGD showed less activation than males with RGU in a manner similar to that observed at pre-test (data not shown). Post-hoc analysis of the caudate finding showed that IGD status was associated with greater activation of the caudate in both males and females, with similar activations observed across males and females with IGD and males with RGU showing greater caudate activation than females with RGU (Figure 3B). A significant positive correlation was found between activation of the caudate and self-reported cravings in the entire sample, and this relationship was significant in females but not males (Figure 3C and D).

\section{Gender-by-group effect at post-pre gaming}

In post-pre analyses, significant gender-by-group interactions were observed in the left DLPFC and the middle/ superior temporal gyrus (Figure 4A; Table 1). Post-hoc analysis of the left DLPFC showed that DLPFC activation was relatively decreased at post-pre gaming among females with IGD, whereas activation was relatively increased at post-pre gaming in females with RGU. In males, DLPFC activation was relatively decreased at post-pre gaming in both the IGD and RGU groups. These findings were significantly different across gender groups within both the RGU to IGD groups (Figure 4B). A negative correlation was found between the brain response changes in the DLPFC at post-pre gaming and self-reported cravings in the entire sample, with the relationship significant among females but not males (Figure 4C and D). The interactions of right middle temporal gyrus and right superior temporal gyrus are presented in the Supplementary Material.

\section{DISCUSSION}

In this study, we examined gender-related differences in subjective and neural responses to gaming cues in before and after an episode of gaming during which a forced break during gaming was introduced. Men and women showed differences in gaming-cue-elicited responses in cortical and striatal regions in manners that were sensitive to group (IGD and RGU) and time (pre-gaming and post-gaming). Our hypotheses were partially supported, and implications are discussed below.

\section{IGD, gender, and blunted DLPFC activation}

In both pre- and post-tests, IGD subjects showed decreased DLPFC activation relative to RGU subjects when facing gaming cues, in both male and female subjects. Multiple studies have indicated that the DLPFC contributes importantly to executive control. In addicted subjects, DLPFC activation may enable individuals to inhibit desires and control the 
Table 2. Gender, diagnosis, and brain activation findings at pre-gaming and post-gaming

\begin{tabular}{|c|c|c|c|c|c|}
\hline Cluster number & $\mathrm{x}, \mathrm{y}, \mathrm{z}^{\mathrm{a}}$ & Peak intensity & Cluster size ${ }^{\mathrm{b}}$ & Region $^{\mathrm{c}}$ & Brodmann's area \\
\hline \multicolumn{6}{|l|}{ Pre-gaming } \\
\hline \multicolumn{6}{|c|}{ Main effect of gender } \\
\hline 1 & $24,68,-3$ & 23.849 & 42 & Right superior frontal gyrus & 10 \\
\hline 2 & $31,-10,43$ & 17.239 & 22 & Right middle frontal gyrus & 5 \\
\hline 3 & $12,-70,1$ & 13.529 & 129 & Right lingual gyrus & \\
\hline 4 & $-52,34,-14$ & 13.015 & 37 & Left inferior frontal gyrus & 47 \\
\hline 5 & $38,-30,-22$ & 12.604 & 28 & Right parahippocampal gyrus & 36 \\
\hline 6 & $66,-4,9$ & 12.213 & 45 & Right superior temporal gyrus & 11 \\
\hline \multicolumn{6}{|c|}{ Main effect of group } \\
\hline 1 & $-26,-10,43$ & 16.794 & 38 & Left middle frontal gyrus & 6 \\
\hline 2 & $-6,-3,-30$ & 11.756 & 26 & Left cingulate gyrus & 24 \\
\hline 3 & $14,32,-30$ & 9.710 & 31 & Right orbital gyrus & 11 \\
\hline \multicolumn{6}{|c|}{ Gender-by-group interactions } \\
\hline 1 & $-21,-9,45$ & 16.25 & 25 & Left DLPFC & 46 \\
\hline \multicolumn{6}{|l|}{ Post-gaming } \\
\hline \multicolumn{6}{|c|}{ Main effect of gender } \\
\hline 1 & $33,-57,26$ & 14.672 & 22 & Right medial temporal gyrus & 39 \\
\hline 2 & $60,35,7$ & 13.526 & 32 & Right inferior frontal gyrus & 46 \\
\hline \multicolumn{6}{|c|}{ Main effect of group } \\
\hline 1 & $-22,13,-38$ & 21.202 & 22 & Left superior temporal gyrus & 38 \\
\hline 2 & $-51,24,-13$ & 11.720 & 25 & Left inferior frontal gyrus & 47 \\
\hline \multicolumn{6}{|c|}{ Gender-by-group interactions } \\
\hline 1 & $-3,0,18$ & 11.14 & 16 & Left caudate & \\
\hline 2 & $-33,3,42$ & 10.34 & 25 & Left DLPFC & 46 \\
\hline \multicolumn{6}{|c|}{ Gender-by-group interactions in post-gaming versus pre-gaming } \\
\hline 1 & $-25,6,45$ & 10.93 & 23 & Left DLPFC & 46 \\
\hline 2 & $72,-36,0$ & 12.04 & 50 & Right middle temporal gyrus & 39 \\
\hline 3 & $69,6,45$ & 13.21 & 36 & Right superior temporal gyrus & 22 \\
\hline
\end{tabular}

Note. DLPFC: dorsolateral prefrontal cortex.

${ }^{\mathrm{a}}$ Peak MNI coordinates. ${ }^{\mathrm{b}}$ Number of voxels. Alphasim correction, $p<.001$; Cluster size $>15$ contiguous voxels. ${ }^{\mathrm{c}}$ The brain regions were referenced to the software Xjview (http://www.alivelearn.net/xjview8) and verified through comparisons with a brain atlas.

extent of participation in reward-seeking behaviors (Enokibara, Trevizol, Shiozawa, \& Cordeiro, 2016; Everitt et al., 2007; Goldstein \& Volkow, 2011; Lee, Park, Namkoong, Kim, \& Jung, 2018; Sofuoglu, DeVito, Waters, \& Carroll, 2013). Changes in activity in the left DLPFC using repetitive transcranial magnetic stimulation and transcranial direct current stimulation may reduce cue-induced craving in individuals with nicotine, cocaine, and methamphetamine dependence (Enokibara et al., 2016; Feil \& Zangen, 2010; Li et al., 2013; Shen, Cao, et al., 2016). Preclinical studies have identified PFC hypoactivity in addiction, and activating the PFC could reduce drug-seeking behaviors in both animals (Chen et al., 2013) and humans (Terraneo et al., 2016). The negative correlation between self-reported craving and DLPFC activation in this study suggests not only that lower DLPFC activation may be accompanied with enhanced cravings for addiction-related cues, but also that enhanced DLPFC activation may be a target for treatment development in IGD as it is in other addictions (Dong, Li, et al., 2017; Wang et al., 2016; Yao et al., 2017).

When considering gender groups, we found that blunted DLPFC activation was observed only in male subjects. According to the role of DLPFC discussed above, the finding may in part explain why male players show higher rates of IGD than female players do. Namely, males in response to gaming cues may show less DLFPC activation and this may relate to poorer executive control over cravings when facing gaming cues, and this possibility warrants direct examination, given the implications relating to prevention and treatment of IGD. Importantly, other brain regions and mechanisms may be important to consider in intervention development for females with IGD.

\section{$I G D$, gender, and increased caudate activation}

At post-gaming, a significant interaction between gender and group was found in the caudate. Further post-hoc analysis of activity in this brain region showed that male as compared to female RGU subjects showed higher caudate activation post-gaming, with males and females with IGD showing similar patterns of activation. Of note, relatively increased caudate activation was observed in male and female subjects with IGD relative to those with RGU, suggesting that this difference in the RGU may relate to resiliency from developing IGD in females relative to males.

The caudate has been described as a component of reward circuitry and may promote motivations to pursue rewards (Dong, Wang, \& Potenza, 2016; Grahn, Parkinson, \& Owen, 2008). Multiple studies and theoretical models have suggested that reward systems contribute to IGD (Brand et al., 2016; Dong, Hu, \& Lin, 2013; Dong et al., 2011; Dong \& Potenza, 2014). Higher activation of the caudate may relate to increased striatal dopamine synthesis 


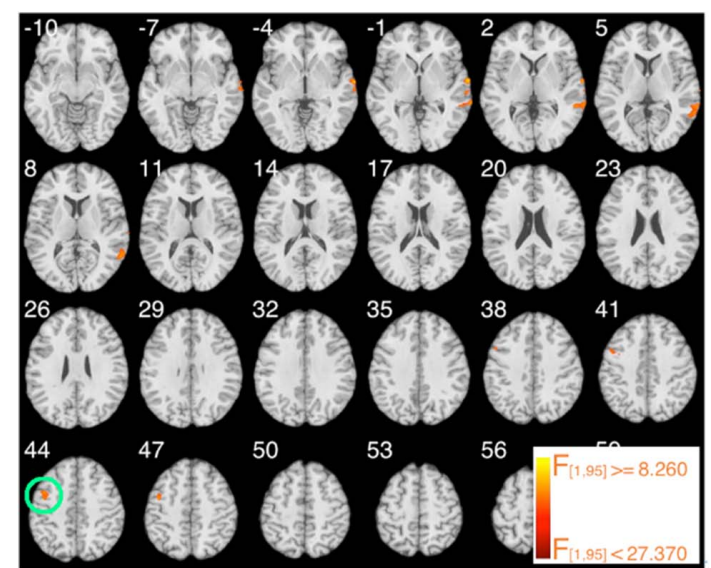

(A)

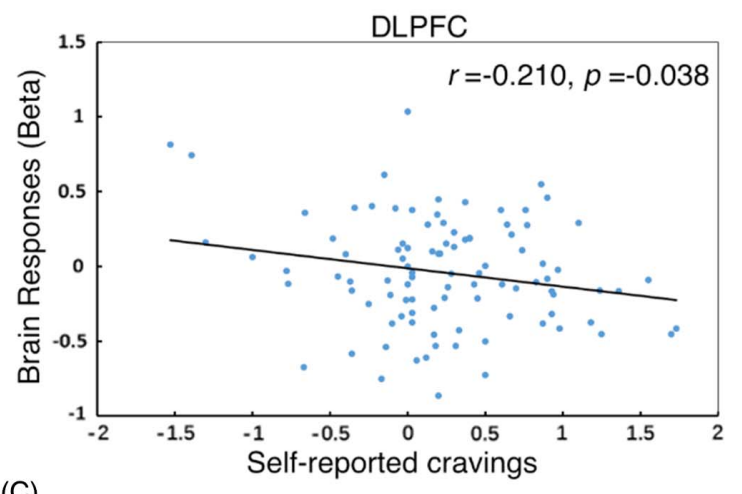

(C)

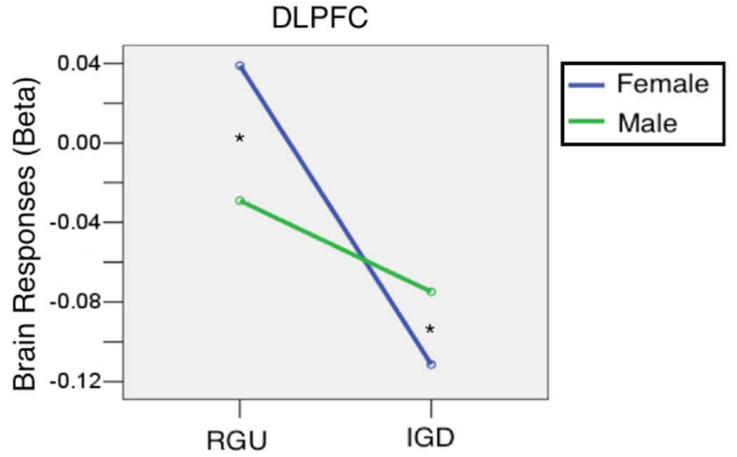

(B)

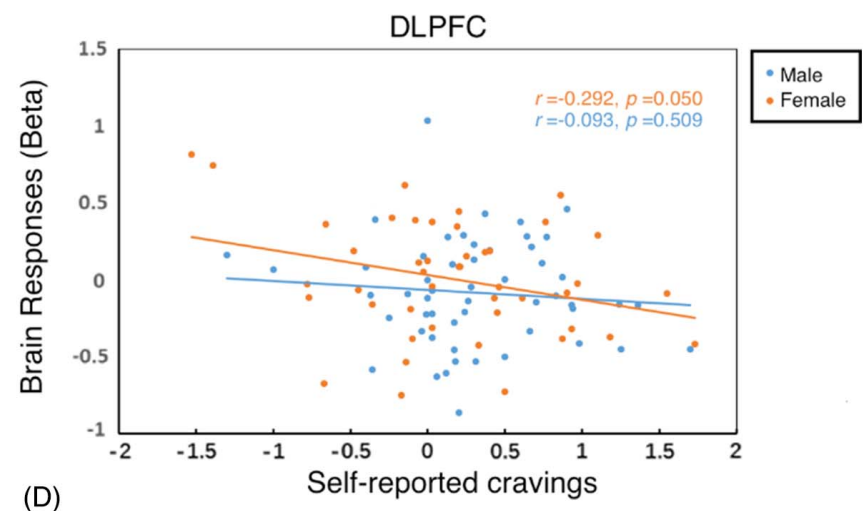

Figure 4. Gender-by-group interaction in post-gaming versus pre-gaming comparison. (A) The DLPFC showed a significant gender-bygroup interaction in the post-gaming versus pre-gaming comparison. (B) Post-hoc analysis showed that the DLPFC activation in IGD relative to RGU subjects was blunted to a greater degree in females as compared to male subjects. Changes in DLPFC activation correlated inversely with self-reported craving in all subjects (C) and in females but not males (D)

(Harle, Zhang, Ma, Yu, \& Paulus, 2016; Perry et al., 2015; van Holst et al., 2017). The positive correlation between caudate activation and self-reported craving suggests that the higher the caudate activates when experiencing gaming cues, the greater the motivation to game.

The current findings suggest specific neural mechanisms underlying craving responses in IGD, consistent with prior findings (Dong et al., 2011; Dong \& Potenza, 2014; Dong, Wang, Wu, \& Potenza, 2017) and extending the understanding to females. Craving may shift people's attention toward addiction-related cues (Sayette, 2016; Tiffany, 1990) and influence the evaluation of addiction-related information (Sayette, Schooler, \& Reichle, 2010), motivating individuals to pursue immediate satisfaction rather than long-term rewards (Balodis \& Potenza, 2015; Berridge \& Kringelbach, 2015; Dong \& Potenza, 2016; Piper, 2015; Wilson et al., 2014). In this study, the positive correlation between caudate activation and self-reported cravings suggests neural mechanisms that may relate to IGD vulnerability and persistence, although these need to be examined directly in future longitudinal studies.

\section{Gender and post-gaming activations during a forced break}

In this study, a forced break was introduced to elicit a deprivation condition. A significant group-by-gender interaction was noted in the left DLPFC for post-gaming versus pre-gaming cue elicitation. Post-hoc analysis showed that within female subjects there was a greater difference in DLPFC activation in the IGD versus RGU groups as compared to that within the male subjects.

Given the role of the DLPFC in executive control as discussed above, the finding raises the possibility that females with IGD may have particular difficulties in controlling their gaming behaviors in the setting of cravings in response to gaming cues following gaming during a forced break (Dong, Wang, Du, et al., 2017). This finding suggests that females with IGD may find it particularly difficult to remit once they have developed IGD. However, these notions are currently speculative and warrant direct examination in future studies. Nonetheless, this interpretation would resonate with gender-related differences in substance addictions, which have observed that females exhibit more rapid escalation from casual drug taking to addiction, exhibit greater withdrawal responses during abstinence, and demonstrate greater poorer treatment outcome relative to males (Becker et al., 2017; Bobzean et al., 2014; Moran-Santa Maria et al., 2014).

\section{Strengths and clinical implications}

This study has multiple strengths. This is the first study to examine gender-related difference in cue elicitation responses in IGD responses. The study includes a sizable 
number of females and a comparison group with comparable levels of gaming.

The current findings have several clinical implications. First, gender-related differences in responses to gaming cues in IGD and RGU subjects suggest differences in mechanisms by which IGD may operate in females and males. These findings may provide a foundation for identifying possible neural markers in developing interventions and evaluating mechanisms linked to treatment outcome. Second, the current findings raise the possibility that gender may need to be considered in the selection of therapies in the treatment of IGD, and the possibility that interventions targeting cravings may operate in a gender-sensitive fashion.

Funding sources: This research was supported by National Science Foundation of China (31371023). Dr. MNP's involvement was supported by the National Center for Responsible Gaming, the Connecticut Department of Mental Health and Addiction Services, and the Connecticut Council on Problem Gambling. The funding agencies did not contribute to the experimental design or conclusions, and the views presented in the manuscript are those of the authors and may not reflect those of the funding agencies.

Authors' contribution: GD designed the task and wrote the first draft of the manuscript. HL, XL, and YW collected and analyzed the data and prepared the figures and tables. XD contributed in collection and preparation of the data. MNP contributed in editing, interpretation, and revision processes. All authors contributed to and have approved the final version of the manuscript.

Conflict of interest: The authors report that they have no financial conflicts of interest with respect to the content of this manuscript.

\section{REFERENCES}

Abrams, K., Krimmel, S., Johnson, S., Cieslowski, K., Strnad, H., Melum, A., \& Kryder, C. (2017). Nicotine deprivation attenuates panic reactivity in smokers: Findings from a placebocontrolled nicotine patch study. Depression and Anxiety, 34(11), 996-1005. doi:10.1002/da.22652

American Psychiatric Association. (2013). Diagnostic and statistical manual of mental disorders (5th ed.). Arlington, VA: American Psychiatric Association.

Balodis, I. M., \& Potenza, M. N. (2015). Anticipatory reward processing in addicted populations: A focus on the monetary incentive delay task. Biological Psychiatry, 77(5), 434-444. doi:10.1016/j.biopsych.2014.08.020

Becker, J. B. (2016). Sex differences in addiction. Dialogues in Clinical Neuroscience, 18(4), 395-402. Retrieved from https:// www.dialogues-cns.org/contents-18-4/dialoguesclinneurosci18-395/

Becker, J. B., McClellan, M. L., \& Reed, B. G. (2017). Sex differences, gender and addiction. Journal of Neuroscience Research, 95(1-2), 136-147. doi:10.1002/jnr.23963
Berridge, K. C., \& Kringelbach, M. L. (2015). Pleasure systems in the brain. Neuron, 86(3), 646-664. doi:10.1016/j.neuron.2015.02.018

Bobzean, S. A. M., DeNobrega, A. K., \& Perrotti, L. I. (2014). Sex differences in the neurobiology of drug addiction. Experimental Neurology, 259, 64-74. doi:10.1016/j.expneurol.2014. 01.022

Borgonovi, F. (2016). Video gaming and gender differences in digital and printed reading performance among 15-year-olds students in 26 countries. Journal of Adolescence, 48, 45-61. doi:10.1016/j.adolescence.2016.01.004

Brand, M., Young, K. S., Laier, C., Wolfling, K., \& Potenza, M. N. (2016). Integrating psychological and neurobiological considerations regarding the development and maintenance of specific Internet-use disorders: An Interaction of PersonAffect-Cognition-Execution (I-PACE) model. Neuroscience and Biobehavioral Reviews, 71, 252-266. doi:10.1016/j. neubiorev.2016.08.033

Breland, A. B., Buchhalter, A. R., Evans, S. E., \& Eissenberg, T. (2002). Evaluating acute effects of potential reduced-exposure products for smokers: Clinical laboratory methodology. Nicotine \& Tobacco Research, 4(42), 131-140. doi:10.1080/ 1462220021000032780

Chen, B. T., Yau, H. J., Hatch, C., Kusumoto-Yoshida, I., Cho, S. L., Hopf, F. W., \& Bonci, A. (2013). Rescuing cocaineinduced prefrontal cortex hypoactivity prevents compulsive cocaine seeking. Nature, 496(7445), 359-362. doi:10.1038/ nature 12024

Desai, R. A., Krishnan-Sarin, S., Cavallo, D., \& Potenza, M. N. (2010). Video-gaming among high school students: Health correlates, gender differences, and problematic gaming. Pediatrics, 126(6), E1414-E1424. doi:10.1542/peds.2009-2706

Detar, D. T. (2011). Understanding the disease of addiction. Primary Care, 38(1), 1-7. doi:10.1016/j.pop.2010.11.001

DeVito, E. E., Worhunsky, P. D., Carroll, K. M., Rounsaville, B. J., Kober, H., \& Potenza, M. N. (2012). A preliminary study of the neural effects of behavioral therapy for substance use disorders. Drug and Alcohol Dependence, 122(3), 228-235. doi:10.1016/j. drugalcdep.2011.10.002

Dong, G., Hu, Y., \& Lin, X. (2013). Reward/punishment sensitivities among Internet addicts: Implications for their addictive behaviors. Progress in Neuro-Psychopharmacology \& Biological Psychiatry, 46, 139-145. doi:10.1016/j.pnpbp.2013.07.007

Dong, G., Hu, Y., Lin, X., \& Lu, Q. (2013). What makes Internet addicts continue playing online even when faced by severe negative consequences? Possible explanations from an fMRI study. Biological Psychology, 94(2), 282-289. doi:10.1016/j. biopsycho.2013.07.009

Dong, G., Huang, J., \& Du, X. (2011). Enhanced reward sensitivity and decreased loss sensitivity in Internet addicts: An fMRI study during a guessing task. Journal of Psychiatric Research, 45(11), 1525-1529. doi:10.1016/j.jpsychires.2011.06.017

Dong, G., Li, H., Wang, L., \& Potenza, M. N. (2017). Cognitive control and reward/loss processing in Internet gaming disorder: Results from a comparison with recreational Internet gameusers. European Psychiatry, 44, 30-38. doi:10.1016/j.eurpsy. 2017.03.004

Dong, G., Lin, X., Hu, Y., Xie, C., \& Du, X. (2015). Imbalanced functional link between executive control network and reward network explain the online-game seeking behaviors in Internet gaming disorder. Scientific Reports, 5, 9197. doi:10.1038/ srep09197 
Dong, G., \& Potenza, M. N. (2014). A cognitive-behavioral model of Internet gaming disorder: Theoretical underpinnings and clinical implications. Journal of Psychiatric Research, 58, 7-11. doi:10.1016/j.jpsychires.2014.07.005

Dong, G., \& Potenza, M. N. (2016). Risk-taking and risky decision-making in Internet gaming disorder: Implications regarding online gaming in the setting of negative consequences. Journal of Psychiatric Research, 73, 1-8. doi:10.1016/j. jpsychires.2015.11.011

Dong, G., Wang, L., Du, X., \& Potenza, M. (2017). Gaming increases craving to gaming-related stimuli in individuals with Internet gaming disorder. Biological Psychiatry: CNNI, 2, 404-412. doi:10.1016/j.bpsc.2017.01.002

Dong, G., Wang, L., Wu, L., \& Potenza, M. (2017). Cognitive control and reward/loss processing in Internet gaming disorder: Results from a comparison with recreational Internet gameusers. European Psychiatry, 44, 30-38. doi:10.1016/j.eurpsy. 2017.03.004

Dong, G. H., Wang, Y. F., \& Potenza, M. N. (2016). The activation of the caudate is associated with correct recollections in a reward-based recollection task. Human Brain Mapping, 37(11), 3999-4005. doi:10.1002/hbm.23290

Enokibara, M., Trevizol, A., Shiozawa, P., \& Cordeiro, Q. (2016). Establishing an effective TMS protocol for craving in substance addiction: Is it possible? American Journal on Addictions, 25(1), 28-30. doi:10.1111/ajad.12309

Everitt, B. J., Hutcheson, D. M., Ersche, K. D., Pelloux, Y., Dalley, J. W., \& Robbins, T. W. (2007). The orbital prefrontal cortex and drug addiction in laboratory animals and humans. Annals of the New York Academy of Sciences, 1121(1), 576-597. doi:10.1196/annals.1401.022

Feil, J., \& Zangen, A. (2010). Brain stimulation in the study and treatment of addiction. Neuroscience and Biobehavioral Reviews, 34(4), 559-574. doi:10.1016/j.neubiorev.2009. 11.006

Field, M., Mogg, K., \& Bradley, B. P. (2004). Eye movements to smoking-related cues: Effects of nicotine deprivation. Psychopharmacology, 173(1-2), 116-123. doi:10.1007/s00213-003$1689-2$

Goldstein, R. Z., \& Volkow, N. D. (2011). Dysfunction of the prefrontal cortex in addiction: Neuroimaging findings and clinical implications. Nature Reviews. Neuroscience, 12(11), 652-669. doi:10.1038/nrn3119

González-Ortega, I., Echeburúa, E., de Corral, P., \& Polo-López, R. (2015). Pathological gambling: Clinical gender differences. In M. Sáenz-Herrero (Ed.), Psychopathology in women: Incorporating gender perspective into descriptive psychopathology (pp. 713-726). Cham, Switzerland: Springer International Publishing.

Grahn, J. A., Parkinson, J. A., \& Owen, A. M. (2008). The cognitive functions of the caudate nucleus. Progress in Neurobiology, 86(3), 141-155. doi:10.1016/j.pneurobio.2008.09.004

Grant, J. E., \& Kim, S. W. (2002). Gender differences in pathological gamblers seeking medication treatment. Comprehensive Psychiatry, 43(1), 56-62. doi:10.1053/comp.2002. 29857

Ha, Y. M., \& Hwang, W. J. (2014). Gender differences in Internet addiction associated with psychological health indicators among adolescents using a National Web-based Survey. International Journal of Mental Health and Addiction, 12(5), 660-669. doi:10.1007/s11469-014-9500-7
Harle, K. M., Zhang, S., Ma, N., Yu, A. J., \& Paulus, M. P. (2016). Reduced neural recruitment for Bayesian adjustment of inhibitory control in methamphetamine dependence. Biological Psychiatry. Cognitive Neuroscience and Neuroimaging, 1(5), 448-459. doi:10.1016/j.bpsc.2016.06.008

Havermans, A., van Schayck, O. C. P., Vuurman, E., Riedel, W. J., \& van den Hurk, J. (2017). Nicotine deprivation elevates neural representation of smoking-related cues in object-sensitive visual cortex: A proof of concept study. Psychopharmacology, 234(16), 2375-2384. doi:10.1007/ s00213-017-4628-3

Hester, R., \& Luijten, M. (2014). Neural correlates of attentional bias in addiction. CNS spectrums, 19(3), 231-238. doi:10. 1017/S1092852913000473

Hu, M., Crombag, H. S., Robinson, T. E., \& Becker, J. B. (2004). Biological basis of sex differences in the propensity to selfadminister cocaine. Neuropsychopharmacology, 29(1), 81-85. doi:10.1038/sj.npp.1300301

Jasinska, A. J., Stein, E. A., Kaiser, J., Naumer, M. J., \& Yalachkov, Y. (2014). Factors modulating neural reactivity to drug cues in addiction: A survey of human neuroimaging studies. Neuroscience and Biobehavioral Reviews, 38, 1-16. doi:10. 1016/j.neubiorev.2013.10.013

Kilts, C. D., Gross, R. E., Ely, T. D., \& Drexler, K. P. (2004). The neural correlates of cue-induced craving in cocaine-dependent women. The American Journal of Psychiatry, 161(2), 233-241. doi:10.1176/appi.ajp.161.2.233

King, D. L., \& Delfabbro, P. H. (2018). The concept of harm in Internet gaming disorder. Journal of Behavioral Addictions, 7(3), 562-564. doi:10.1556/2006.7.2018.24

Kiraly, O., Griffiths, M. D., King, D. L., Lee, H. K., Lee, S. Y., Banyai, F., Zsila, Á., Takacs, Z. K., \& Demetrovics, Z. (2017). Policy responses to problematic video game use: A systematic review of current measures and future possibilities. Journal of Behavioral Addictions, 7(3), 503-517. doi:10.1556/2006. 6.2017 .050

Ko, C.-H., Yen, J.-Y., Chen, S.-H., Wang, P.-W., Chen, C.-S., \& Yen, C.-F. (2014). Evaluation of the diagnostic criteria of Internet gaming disorder in the DSM-5 among young adults in Taiwan. Journal of Psychiatric Research, 53, 103-110. doi:10.1016/j.jpsychires.2014.02.008

Kober, H., Lacadie, C. M., Wexler, B. E., Malison, R. T., Sinha, R., \& Potenza, M. N. (2016). Brain activity during cocaine craving and gambling urges: An fMRI study. Neuropsychopharmacology, 41(2), 628-637. doi:10.1038/npp.2015.193

Krishnan-Sarin, S., Balodis, I. M., Kober, H., Worhunsky, P. D., Liss, T., Xu, J. S., \& Potenza, M. N. (2013). An exploratory pilot study of the relationship between neural correlates of cognitive control and reduction in cigarette use among treatment-seeking adolescent smokers. Psychology of Addictive Behaviors, 27(2), 526-532. doi:10.1037/a0032479

Kuss, D. J., \& Griffiths, M. D. (2012). Internet gaming addiction: A systematic review of empirical research. International Journal of Mental Health and Addiction, 10(2), 278-296. doi:10.1007/ s11469-011-9318-5

Lecrubier, Y., Sheehan, D. V., Weiller, E., Amorim, P., Bonora, I., Sheehan, K. H., Janavs, J., \& Dunbar, G. C. (1997). The Mini International Neuropsychiatric Interview (MINI). A short diagnostic structured interview: Reliability and validity according to the CIDI. European Psychiatry, 12(5), 224-231. doi:10.1016/S0924-9338(97)83296-8 
Lee, D., Park, J., Namkoong, K., Kim, I. Y., \& Jung, Y. C. (2018). Gray matter differences in the anterior cingulate and orbitofrontal cortex of young adults with Internet gaming disorder: Surface-based morphometry. Journal of Behavioral Addictions, 7(1), 21-30. doi:10.1556/2006.7.2018.20

Li, L., Yu, Q., Zhang, L., \& Jin, S. (2015). The gender difference on Internet addictive among adolescent: The mediation effect of the differentiation of social and psychological situation in school. Chinese Journal of Clinical Psychology, 23(6), 1044-1048.

Li, X. B., Hartwell, K. J., Owens, M., LeMatty, T., Borckardt, J. J., Hanlon, C. A., Brady, K. T., \& George, M. S. (2013). Repetitive transcranial magnetic stimulation of the dorsolateral prefrontal cortex reduces nicotine cue craving. Biological Psychiatry, 73(8), 714-720. doi:10.1016/j.biopsych.2013.01.003

Lukavska, K. (2018). The immediate and long-term effects of time perspective on Internet gaming disorder. Journal of Behavioral Addictions, 7(1), 44-51. doi:10.1556/2006.6.2017.089

Montag, C., \& Reuter, M. (2015). Internet addiction: Neuroscientific approaches and therapeutical interventions. Cham, Switzerland: Springer Publishing Company, Incorporated.

Moran-Santa Maria, M. M., Flanagan, J., \& Brady, K. (2014). Ovarian hormones and drug abuse. Current Psychiatry Reports, 16(11), 511. doi:10.1007/s11920-014-0511-7

Perry, A. N., Westenbroek, C., Jagannathan, L., \& Becker, J. B. (2015). The roles of dopamine and $\alpha 1$-adrenergic receptors in cocaine preferences in female and male rats. Neuropsychopharmacology, 40(12), 2696-2704. doi:10.1038/npp. 2015.116

Petry, N. M., Rehbein, F., Gentile, D. A., Lemmens, J. S., Rumpf, H. J., Mößle, T., Bischof, G., Tao, R., Fung, D. S., Borges, G., Auriacombe, M., González Ibáñez, A., Tam, P., \& O’Brien, C. P. (2014). An international consensus for assessing Internet gaming disorder using the new DSM-5 approach. Addiction, 109(9), 1399-1406. doi:10.1111/add.12457

Petry, N. M., Zajac, K., \& Ginley, M. K. (2018). Behavioral addictions as mental disorders: To be or not to be? Annual Review of Clinical Psychology, 14(1), 399-423. doi:10.1146/ annurev-clinpsy-032816-045120

Piper, M. E. (2015). Withdrawal: Expanding a key addiction construct. Nicotine \& Tobacco Research, 17(12), 1405-1415. doi:10.1093/ntr/ntv048

Potenza, M. N., Balodis, I. M., Franco, C. A., Bullock, S., Xu, J., Chung, T., \& Grant, J. E. (2013). Neurobiological considerations in understanding behavioral treatments for pathological gambling. Psychology of Addictive Behaviors, 27(2), 380-392. doi:10.1037/a0032389

Potenza, M. N., Hong, K., Lacadie, M., Fulbright, R., Tuit, K. L., \& Sinha, R. (2012). Neural correlates of stress-induced and cue-induced drug craving: Influences of sex and cocaine dependence. American Journal of Psychiatry, 169(4), 406-414. doi:10.1176/appi.ajp.2011.11020289

Potenza, M. N., Steinberg, M. A., McLaughlin, S. D., Wu, R., Rounsaville, B. J., \& O'Malley, S. S. (2001). Gender-related differences in the characteristics of problem gamblers using a gambling helpline. The American Journal of Psychiatry, 158(9), 1500-1505. doi:10.1176/appi.ajp.158.9.1500

Potenza, M. N., Steinberg, M. A., Skudlarski, P., Fulbright, R. K., Lacadie, C. M., Wilber, M. K., Rounsaville, B. J., Gore, J. C., \& Wexler, B. E. (2003). Gambling urges in pathological gambling: A functional magnetic resonance imaging study.
Archives of General Psychiatry, 60(8), 828-836. doi:10.1001/ archpsyc.60.8.828

Przybylski, A. K., Weinstein, N., \& Murayama, K. (2017). Internet gaming disorder: Investigating the clinical relevance of a new phenomenon. The American Journal of Psychiatry, 174(3), 230-236. doi:10.1176/appi.ajp.2016.16020224

Robinson, T. E., \& Berridge, K. C. (2008). The incentive sensitization theory of addiction: Some current issues. Philosophical Transactions of the Royal Society B-Biological Sciences, 363(1507), 3137-3146. doi:10.1098/rstb.2008.0093

Rumpf, H. J., Achab, S., Billieux, J., Bowden-Jones, H., Carragher, N., Demetrovics, Z., Higuchi, S., King, D. L., Mann, K., Potenza, M., Saunders, J. B., Abbott, M., Ambekar, A., Aricak, O. T., Assanangkornchai, S., Bahar, N., Borges, G., Brand, M., Chan, E. M., Chung, T., Derevensky, J., Kashef, A. E., Farrell, M., Fineberg, N. A., Gandin, C., Gentile, D. A., Griffiths, M. D., Goudriaan, A. E., Grall-Bronnec, M., Hao, W., Hodgins, D. C., Ip, P., Király, O., Lee, H. K., Kuss, D., Lemmens, J. S., Long, J., Lopez-Fernandez, O., Mihara, S., Petry, N. M., Pontes, H. M., Rahimi-Movaghar, A., Rehbein, F., Rehm, J., Scafato, E., Sharma, M., Spritzer, D., Stein, D. J., Tam, P., Weinstein, A., Wittchen, H. U., Wölfling, K., Zullino, D., \& Poznyak, V. (2018). Including gaming disorder in the ICD-11: The need to do so from a clinical and public health perspective. Journal of Behavioral Addictions, 7(3), 556-561. doi:10.1556/2006.7.2018.59

Sanchis-Segura, C., \& Becker, J. B. (2016). Why we should consider sex (and study sex differences) in addiction research. Addiction Biology, 21(5), 995-1006. doi:10.1111/adb.12382

Sayette, M. A. (2016). The role of craving in substance use disorders: Theoretical and methodological issues. Annual Review of Clinical Psychology, 12(1), 407-433. doi:10.1146/ annurev-clinpsy-021815-093351

Sayette, M. A., Schooler, J. W., \& Reichle, E. D. (2010). Out for a smoke: The impact of cigarette craving on zoning out during reading. Psychological Science, 21(1), 26-30. doi:10.1177/ 0956797609354059

Shen, C. H., Ratan, R., Cai, Y. D., \& Leavitt, A. (2016). Do men advance faster than women? Debunking the gender performance gap in two massively multiplayer online games. Journal of Computer-Mediated Communication, 21(4), 312-329. doi:10.1111/jcc4.12159

Shen, Y., Cao, X. Y., Tan, T., Shan, C. L., Wang, Y. J., Pan, J. B., He, H., \& Yuan, T. F. (2016). 10-Hz repetitive transcranial magnetic stimulation of the left dorsolateral prefrontal cortex reduces heroin cue craving in long-term addicts. Biological Psychiatry, 80(3), E13-E14. doi:10.1016/j.biopsych.2016.02.006

Sinha, R., \& Li, C. S. (2007). Imaging stress- and cue-induced drug and alcohol craving: Association with relapse and clinical implications. Drug and Alcohol Review, 26(1), 25-31. doi:10.1080/09595230601036960

Sofuoglu, M., DeVito, E. E., Waters, A. J., \& Carroll, K. M. (2013). Cognitive enhancement as a treatment for drug addictions. Neuropharmacology, 64, 452-463. doi:10.1016/j. neuropharm.2012.06.021

Starcevic, V., \& Billieux, J. (2018). Precise estimates of gamingrelated harm should guide regulation of gaming. Journal of Behavioral Addictions, 7(3), 522-525. doi:10.1556/2006.7. 2018.54

Taylor, A. J., Langdon, M., \& Campion, P. (2005). Smuggled tobacco, deprivation and addiction. European Journal of Public Health, 15(4), 399-403. doi:10.1093/eurpub/cki006 
Terraneo, A., Leggio, L., Saladini, M., Ermani, M., Bonci, A., \& Gallimberti, L. (2016). Transcranial magnetic stimulation of dorsolateral prefrontal cortex reduces cocaine use: A pilot study. European Neuropsychopharmacology, 26(1), 37-44. doi:10.1016/j.euroneuro.2015.11.011

Tiffany, S. T. (1990). A cognitive model of drug urges and druguse behavior: Role of automatic and nonautomatic processes. Neuropsychology Review, 97(2), 147-168.

van Holst, R. J., Sescousse, G., Janssen, L. K., Janssen, M., Berry, A. S., Jagust, W. J., \& Cools, R. (2017). Increased striatal dopamine synthesis capacity in gambling addiction. Biological Psychiatry, 83(12), 1036-1043. doi:10.1016/j.biopsych.2017. 06.010

Viriyavejakul, C. (2008). Recreational gaming behavior of undergraduate students in Thailand. In K. McFerrin, R. Weber, R. Carlsen, \& D. Willis (Eds.), Proceedings of SITE 2008-Society for Information Technology \& Teacher Education International Conference (pp. 4948-4955). Las Vegas, NV: Association for the Advancement of Computing in Education.

Volkow, N. D., Wang, G. J., Tomasi, D., \& Baler, R. D. (2013). Unbalanced neuronal circuits in addiction. Current Opinion in Neurobiology, 23(4), 639-648. doi:10.1016/j.conb.2013. 01.002

Wang, Y., Wu, L., Wang, L., Zhang, Y., Du, X., \& Dong, G. (2016). Impaired decision-making and impulse control in
Internet gaming addicts: Evidence from the comparison with recreational Internet game users. Addiction Biology, 22(6), 1610-1621. doi:10.1111/adb. 12458

Wilson, S. J., Delgado, M. R., McKee, S. A., Grigson, P. S., MacLean, R. R., Nichols, T. T., \& Henry, S. L. (2014). Weak ventral striatal responses to monetary outcomes predict an unwillingness to resist cigarette smoking. Cognitive, Affective \& Behavioral Neuroscience, 14(4), 1196-1207. doi:10.3758/ s13415-014-0285-8

Yao, Y. W., Liu, L., Ma, S. S., Shi, X. H., Zhou, N., Zhang, J. T., \& Potenza, M. N. (2017). Functional and structural neural alterations in Internet gaming disorder: A systematic review and meta-analysis. Neuroscience and Biobehavioral Reviews, 83, 313-324. doi:10.1016/j.neubiorev.2017.10.029

Young, K. (2009). Internet addiction: Diagnosis and treatment considerations. Journal of Contemporary Psychotherapy, 39(4), 241-246. doi:10.1007/s10879-009-9120-x

Zakiniaeiz, Y., Cosgrove, K. P., Mazure, C. M., \& Potenza, M. N. (2017). Does telescoping exist in male and female gamblers? Does it matter? Frontiers in Psychology, 8, 1510. doi:10.3389/ fpsyg.2017.01510

Zakiniaeiz, Y., Cosgrove, K. P., Potenza, M. N., \& Mazure, C. M. (2016). Balance of the sexes: Addressing sex differences in preclinical research. The Yale Journal of Biology and Medicine, 89(2), 255-259. 